\title{
Development and Validation of a Stability-indicating RP-HPLC Method for Estimation of Metformin and Rosuvastatin along with Impurities from a Combined Oral Solid Dosage Form
}

\author{
D. SANGEETHAAND M. K. VADLAMUDI ${ }^{1 *}$
}

School of Advanced Sciences, VIT University, Vellore-632 014, ${ }^{1}$ Analytical Research and Development, Ashland India Private Limited, Hyderabad-500 078, India

Sangeetha and Vadlamudi: Stability-indicating RP-HPLC for Determination of Impurities in MET-ROS OSDF

\begin{abstract}
The objective of current study was to develop and validate a stability-indicating reversed-phase highperformance liquid chromatography for simultaneous quantification of impurities in metformin sustained release-rosuvastatin immediate release combined oral solid dosage form as per International Conference on Harmonisation guidelines. Chromatographic separation was achieved using a Waters high performance liquid chromatography system with a YMC-Pack ODS-A $100 \times 4.6 \mathrm{~mm} ; 3 \mu \mathrm{m}$ column. Mobile phase A comprised of $20 \mathrm{mM}$ ammonium acetate:acetonitrile $(9: 1 \mathrm{v} / \mathrm{v}) \mathrm{pH} \mathrm{3.5}$, and mobile phase B, consisted of $20 \mathrm{mM}$ ammonium acetate:acetonitrile:methanol (3:5:2 v/v/v) $\mathrm{pH} 3.5$. The gradient program was set as (T/\% B) 0/30, 5/30, 10/50, 30/50, 40/80, 42/30 and 45/30, which pumped at a rate of $0.9 \mathrm{ml} / \mathrm{min}$. About $10 \mu \mathrm{l}$ of sample solutions were injected and monitored at $240 \mathrm{~nm}$. Column temperature and sample compartment was maintained at $25^{\circ}$ and $5^{\circ}$, respectively. Forced degradation studies revealed that the peak threshould was more than the peak purity and no purity flag was observed. Repeatability, intra, and inter-day precision results were well within the tolerable limits. Limits of detection were found to be $0.10,0.05,0.15,0.20$ and $0.40 \mathrm{ppm}$ and limits of quantitation as $0.30,0.15,0.45,0.60$ and $1.0 \mathrm{ppm}$ for metformin, rosuvastatin, rosuvastatin impurity $A, B$, and $C$, respectively. The correlation coefficient of linearity for metformin, rosuvastatin and its impurities were found to be $\geq \mathbf{0 . 9 9 9}$. The method recovery was found between 99 and $102 \%$. The proposed method appeared to be a simple, rapid, economical, accurate, specific, robust and able to distinguish the two key components from their degradants, impurities, and excipients. Therefore, current method could be applied successfully for stability and routine examination.
\end{abstract}

Key words: Stability-indicating RP-HPLC, metformin, rosuvastatin, ICH guidelines, forced degradation studies and validation

Metformin hydrochloride (MET), chemically 1,1-dimethylbiguanide, was initially developed from a herb, Galega officinalis and first manufactured in 1922 in Dublin as a blood glucose lowering agent ${ }^{[1,2]}$. It is also beneficial for obese diabetic people ${ }^{[1,3]}$. MET first introduced into clinic in 1950s has been extensively used as a first-line therapy for type 2 diabetes people. MET regulates glucose metabolism principally via preventing hepatic glucose production ${ }^{[4-7]}$. Recently, MET has found to be useful in the treatment of various cancers especially prostate, colon, and breast ${ }^{[8-10]}$.

Rosuvastatin calcium (ROS), chemically calcium;(E,3R,5S)-7-[4-(4-fluorophenyl)-2-[methyl (methylsulfonyl)amino]-6-propan-2-ylpyrimidin-5- yl]-3,5-dihydroxyhept-6-enoate, which is a statin, used clinically to treat hypercholesterolemia in both patients with recognized cardiovascular illness as well as those at high risk to develop atherosclerosis ${ }^{[11-13]}$.

As per the American Diabetes Association guiding principle, adults with type 2 diabetes mellitus should ideally have $<100 \mathrm{mg} / \mathrm{dl}$ of low-density lipoprotein (LDL) cholesterol, if necessary with the help of

This is an open access article distributed under the terms of the Creative Commons Attribution-NonCommercial-ShareAlike 3.0 License, which allows others to remix, tweak, and build upon the work non-commercially, as long as the author is credited and the new creations are licensed under the identical terms

Accepted 28 February 2019

Revised 20 November 2018

Received 02 March 2018

*Address for correspondence

E-mail: manojvadlamudi2023@gmail.com

March-April 2019

Indian Journal of Pharmaceutical Sciences 
statins as a first-line therapy ${ }^{[13,14]}$. Among atorvastatin, simvastatin, rosuvastatin, and pravastatin, ROS was found to be more efficient in reducing LDL cholesterol in hypercholesterolemic patients ${ }^{[15-17]}$. In general, adults diagnosed with diabetes have high or borderline total cholesterol levels. Hence treatment regimen should include statins to maintain the cholesterol level and to reduce the risk of heart attack. A recent patent application on pharmaceutical composition comprising MET and ROS appealing the benefit of diminishing side effects produced by statins, enhances safety and patient's convenience and compliance with its one per day dosage ${ }^{[18,19]}$. Diabetes frequently is connected with quicker atherosclerosis leading to cardiovascular illness and exposes the type 2 diabetic patients to 2 to 4 times greater hazard of developing heart-related problems resulting in higher mortality rates due to atherosclerotic complications. Higher glycemic levels in the body might cause essential tissue malfunction, increases lipid biosynthesis and dyslipidaemia. hyperglycaemia may increase the formation of reactive oxygen species, which result in increased glycation products. Glycation of lipoproteins and VLDL together leads to diabetesinduced dyslipidaemia ${ }^{[20-22]}$.

Diabetic patients might also end up with dyslipidemia, in which case monotherapy with an antidiabetic agent might not be adequate to reach the target glycemic and lipid goals, consequently a combination of antidiabetic and antidyslipidemic drug might be essential to attain it. Novel amalgamation of sustained release (SR) MET and immidiate release (IR) ROS is recommended for glycemic as well as lipid control in the blood ${ }^{[20,23]}$.
Literature survey disclosed that there were only limited approaches available, which aimed at the simultaneous determination of MET and ROS in a single methodology ${ }^{[19,20,24]}$. Few other studies discussed about simultaneous determination of MET and $\operatorname{ROS}^{[19,20,24]}$. Liquid chromatography combination method was developed and validated for assay in human plasma ${ }^{[25]}$. However, no method was reported for simultaneous determination of MET, ROS and its impurities. The eventual aim of this effort is to develop and validate a single reversed-phase high-performance liquid chromatography (RP-HPLC) method to afford simultaneous quantitation of MET, ROS, ROS impurity A (ROS A), ROS impurity B (ROS B) and ROS impurity $C$ (ROS $C$ ). The structures of MET, ROS, ROS A, B, and C are shown in fig. 1.

\section{MATERIALS AND METHODS}

Chemicals and reagents used were of analytical grade. Acetonitrile, methanol, ammonium acetate and orthophosphoric acid were procured from MerckGermany, and Milli-Q water was obtained from a Millipore system (Merck-Millipore, Bradford). Drug substances, excipients, and impurities were procured from Ashland India Pvt., Ltd., Hyderabad.

\section{Chromatographic conditions:}

Waters Alliance HPLC e2695 was connected to a 2998 PDA detector using the Empower3 software. The chromatographic separation was achieved on YMCPack ODS-A $100 \times 4.6 \mathrm{~mm} ; 3 \mu \mathrm{m}$ column. Mobile phase A contained $20 \mathrm{mM}$ ammonium acetate:acetonitrile $(\mathrm{pH} 3.5,9: 1 \mathrm{v} / \mathrm{v})$ and mobile phase $\mathrm{B}$ contained a

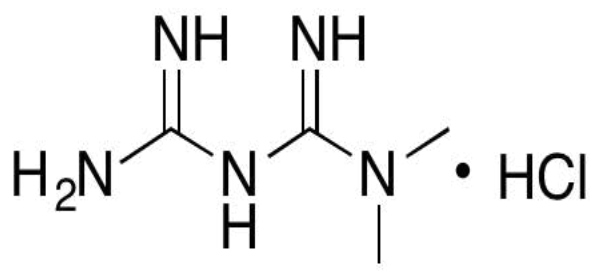

c

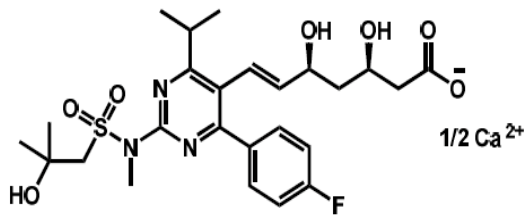

b

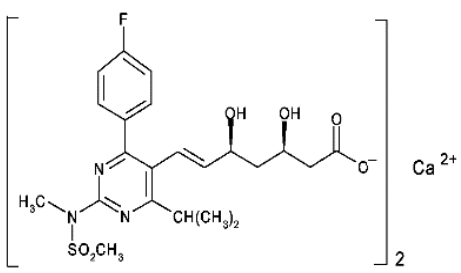

d

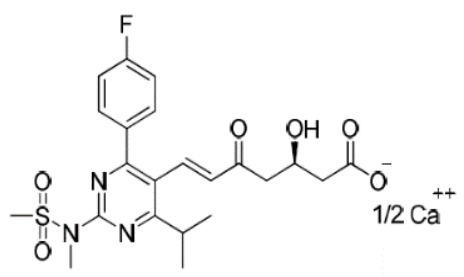

Fig. 1: Structures of MET, ROS, and impurities ROS A, B and C Structures of a. metformin (MET), b. rosuvastatin (ROS) and ROS impurities c. ROS A, d. ROS B and e. ROS C 
$20 \mathrm{mM}$ ammonium acetate:acetonitrile:methanol $(\mathrm{pH}$ $3.5,3: 5: 2 \mathrm{v} / \mathrm{v} / \mathrm{v})$. The gradient program was set as (T/\% B) 0/30, 5/30, 10/50, 30/50, 40/80, 42/30 and $45 / 30$, which pumped at $0.9 \mathrm{ml} / \mathrm{min}$. Column and sample compartment was maintained at 25 and $5^{\circ}$, respectively. About $10 \mu \mathrm{l}$ of sample solutions were injected and monitored at $240 \mathrm{~nm}$.

\section{Preparation of pharmaceutical oral solid dosage form (OSDF):}

In-house tablets were manufactured by first preparing MET SR blend using the hot melt extrusion and the ROS IR blend using the direct compression process separately and compressing together these two as a bilayered tablet. Core tablets were coated with moisture guard materials. In vitro dissolution was performed as per Indian Pharmacopeia (IP) monograph and the results are tabulated in the Table 1.

\section{Sample preparation for in-house or marketed generic MET SR/ROS IR OSDF:}

Twenty tablets of either in-house prepared or marketed generic MET SR/ROS IR were ground and triturated into a fine, evenly size powder in a mortar. Powder equivalent to the average tablet weight was weighed and transferred to a $25 \mathrm{ml}$ volumetric flask, which contained $20 \mathrm{ml}$ of methanol. The mixture was sonicated for $30 \mathrm{~min}$ and the volume was made up tp the mark with methanol after the solution reached room temperature. The contents of the volumetric flask were centrifuged at $5000 \mathrm{rpm}$ for $10 \mathrm{~min}$, filtered through $0.45 \mu \mathrm{m}$ polyvinylidene difluoride membrane filter and the clear filtrate was injected in to the HPLC.

\section{Analytical method development:}

During method development, different trials were carried out to shorten the runtime, improve the resolution and retain MET. All experiments were conducted using the mobile phase A and B. However, the method development was carried out by changing the gradient programs, flow rates, and column chemistry.

\section{Determination of relative response factors (RRF):}

RRF was calculated by injecting all the impurities including MET and ROS as an unknown sample from 0.5 to 6 ppm onto the HPLC system. RRF was estimated by dividing the slope of each impurity to the slope of ROS from the linearity curve. The relative retention time of MET, ROS A, ROS, ROS B and ROS C was found to be $0.06,0.88,1.00,1.07$ and $1.59 \mathrm{~min}$, respectively. The RRF of MET, ROS A, ROS, ROS B and ROS C was found to be 1.11, 0.77, 1.00, 0.82 and 0.29 , respectively.

System suitability study (SSS) is an integral part of the chromatographic system to ensure that chromatographic system are adequate for examination to be done. SSS was carried out on a freshly prepared standard solution containing ROS, ROS A, and ROS B to inspect the resolution between the peaks. The resolution was found to be 5.1 between ROS A and ROS. The resolution was found to be 2.9 between ROS and ROS B.

Robustness is a part of the analytical process where the degree of its capacity to persist unaffected by minor and deliberate variations in method parameters and also to confirm its reliability throughout the regular analysis. It was evaluated by making changes in the buffer $\mathrm{pH}( \pm 0.1)$, least mobile phase composition $( \pm 10 \%)$, flow rate $( \pm 0.1 \mathrm{ml} / \mathrm{min})$, oven temperature $\left( \pm 2^{\circ}\right)$, wavelength $( \pm 2 \mathrm{~nm})$ and the column of a different lot of stationary phase ${ }^{[26,27]}$.

Validation is a process by which method gets an assurance for intended use to perform a regular analysis, and it can also judge the quality, accuracy, and consistency of results. Moreover, it's an essential part of good analytical practice ${ }^{[26]}$. As per

TABLE 1: DISSOLUTION ANALYSIS

\begin{tabular}{|c|c|c|c|c|}
\hline \multicolumn{5}{|c|}{ MET \% Dissolution } \\
\hline Time (h) & $\begin{array}{c}\text { Specification as per IP } \\
\text { monograph, \% }\end{array}$ & $\begin{array}{l}\text { Marketed generic } \\
\text { tablets-1 }\end{array}$ & $\begin{array}{l}\text { Marketed generic } \\
\text { tablets- } 2\end{array}$ & In-house tablets \\
\hline 0.5 & NA & 24 & 35 & 28 \\
\hline 1 & $25-50$ & 36 & 48 & 44 \\
\hline 3 & $45-75$ & 67 & 75 & 71 \\
\hline 6 & NA & 89 & 93 & 100 \\
\hline 10 & NLT 80 & 101 & 102 & 102 \\
\hline
\end{tabular}

ROS \% dissolution

Time (min)

Specification as per IP monograph, \%

Marketed tablets-1

Marketed tablets-2

101

In-house tablets

98

101 
International Conference on Harmonisation (ICH) guidelines specificity, precision, limit of detection, limit of quantization, linearity, accuracy and range were considered for the validation ${ }^{[26]}$. Specificity is a capability of measuring the analyte apparently in the existence of compounds, which might be in the form of a matrix, impurities, and degradants ${ }^{[26]}$.

Precision indicates the closeness of agreement among the sequence of measurements attained after several samplings of a homogeneous sample under similar method parameters. As per ICH guidelines, precision divided as repeatability, intermediate precision, and reproducibility ${ }^{[26]}$. Precision sample solution contains MET, ROS, ROS A, B and C. Repeatability established by injecting the six sample preparations under the similar operating circumstances. Intermediate precision conducted nine measures each three come by changing the analyst, instrument and day. Reproducibility comes under the inter-lab evaluation, hence not covered in this study.

Limit of detection is the lowermost quantity of analyte in a sample which can be detected but need not be inherently quantitated as a precise value. Limit of quantitation (LOQ) is the lowermost quantity of analyte in a sample, which needs to be quantitatively determined with appropriate precision and accuracy ${ }^{[26]}$. LOD and LOQ established using calibration curve method by injecting the series of concentrations, which includes detection limit range containing MET, ROS, ROS A, B, and C. LOD $=(3.3 \sigma) / \mathrm{S} ; \mathrm{LOQ}=(10 \sigma) / \mathrm{S}$, where, $\sigma$ is the standard deviation of area response, $\mathrm{S}$ is the slope of the calibration curve.

Linearity is an analytical procedure, which demonstrates that area responses are directly proportional to the concentration of an analyte in a specified range ${ }^{[26]}$. Five concentration stages established between LOQ and $150 \%$ concerning test level for MET, ROS, ROS A, $\mathrm{B}$, and $\mathrm{C}$.

Accuracy is an analytical procedure, which delivers nearness of agreement among the current actual/ reference value, and the value found ${ }^{[26]}$. Accuracy evaluated using 12 determinations over four concentration levels of LOQ, 50, 100 and $150 \%$ concerning sample test level. Range is a systematic analytical process, which exhibits the appropriate precision, accuracy, and linearity over the interval range of higher and lower concentration of impurities in the sample ${ }^{[26]}$. It's already been covered in accuracy and linearity parameters.

\section{Forced degradation studies:}

Chemical stability of a drug substance is a matter of great concern as it affects the safety and efficacy of the drug product. The US-FDA and ICH guidance committee stated the necessity of stability testing data is to recognize, how the excellence of a drug product changes with time under the influence of various environmental factors. Forced degradation is a process that includes the degradation of drug products at conditions simpler than accelerated conditions thus generate degradation products that can be studied to determine the stability of the molecule ${ }^{[28]}$. Information about the stability of a molecule helps in selecting proper formulation, package, and storage conditions which are crucial for regulatory documentation. The details of ICH guideline proposed that stress testing is planned to identify the likely degradation products, which further assists in the determination of the intrinsic stability of the molecule and will establish the degradation pathways to validate the stability indicating procedures ${ }^{[29-31]}$. To prove that the method is stabilityindicating, equivalent tablet powder of MET SR/ROS IR in-house combination tablets exposed forcefully to acidic, alkaline, oxidative, thermal, neutral and photolytic conditions.

\section{Acidic, alkaline, oxidative and neutral conditions:}

About $5 \mathrm{ml}$ of each $0.1 \mathrm{~N}$ hydrochloric acid, $0.1 \mathrm{~N}$ sodium hydroxide, $3 \%$ hydrogen peroxide and water added to separate stock solutions of MET placebo, ROS placebo, and MET SR/ROS IR combination in-house tablet powder, respectively. The respective solutions refluxed at $80^{\circ}$ for $4 \mathrm{~h}$. Further, the acid- and alkaliexposed solutions were neutralized by adding acid to alkaline and vice versa for an acid-refluxed solution and then made up to mark with methanol; again, further diluted respective sample solutions to assay concentrations for determinations of mass balance.

\section{Thermal condition:}

Stock solutions of MET placebo, ROS placebo, MET SR/ROS IR combination in-house tablet powder were exposed thermally at $105^{\circ}$ for a week. Sample solutions were prepared as per the concentrations and injected onto the RP-HPLC system.

\section{Photo stability condition:}

Stock solutions of MET placebo, ROS placebo, and MET SR/ROS IR combination in-house tablet powder exposed to light providing a total luminosity of $>1.2$ 
million lux hours and combined with the ultraviolet energy of $>200$-watt-h/ $/ \mathrm{m}^{2}$. Sample solutions were prepared as per the concentrations and injected onto the RP-HPLC system.

\section{Sample analysis for impurities:}

Solution stability of drug product after preparation should be assessed according to the test method because most of the analyses utilizes an auto-sampler with an overnight sequence and the sample will be in solution form for $h$ in the laboratory environment before injecting onto HPLC. So, it is of worry specifically for drugs that can undergo degradation by adhesion to glassware and hydrolysis ${ }^{[32]}$. As part of solution stability, spiked impurity solutions were analyzed initially and at different time intervals of 24,48 , and $72 \mathrm{~h}$, at room $\left(25^{\circ}\right)$ and refrigerator $\left(5^{\circ}\right)$ temperature as per developed and validated method. One in-house and four individual marketed generic formulations were analyzed as per the developed and validated method of analysis.

\section{RESULTS AND DISCUSSION}

In trial 1 and 2, MET eluted in void time and the run time was about $60 \mathrm{~min}$. In trial 3, YMC-Pack ODS-A $100 \times 4.6 \mathrm{~mm} ; 3 \mu \mathrm{m}$ column replaced with Unisol C18, MET was eluted after void time. However, ROS C not eluted within $40 \mathrm{~min}$, which might be due to its high carbon loading present in Unisol column as compared to YMC-pack. Finally, in trial 4 MET was eluted after void volume by modifying the gradient program using YMC-Pack ODS-A 100×4.6 mm; $3 \mu \mathrm{m}$ column.
Table 2 shows all details of complete development trials, and developed chromatogram is shown in fig. 2 a.

As a part of robustness, no significant variations in resolution between the peaks of ROS A, ROS and ROS B was observed even after small and deliberate changes in the method parameters. No interference was observed with the retention period of both the molecules and its impurities from degradants, placebo, which used as excipients for making up the formulation.

Forced degradation study correspondingly confirmed the specificity of the method. As a part of peak purity study, peak threshold was found to be higher than angle and no flag for both the analytes was observed. Degradation study revealed that MET was degraded in alkaline condition only, whereas ROS degraded in acidic, alkaline, oxidative, and photolytic conditions. The results displayed in Table 3 and the individual chromatograms are given in figs. $2 \mathrm{~b}-\mathrm{g}$.

Repeatability established regarding coefficient of variation and the values were found to be between 1.8 and $2.7 \%$ (Table 4). Intermediate precision made regarding coefficient of variation and the values were found to be between 2.6 and $2.8 \%$. The fallouts positioned in Table 4. LOD for MET, ROS, ROS A, $\mathrm{B}, \mathrm{C}$ were determined as $0.10,0.05,0.15,0.20,0.40$ ppm individually. LOQ for MET, ROS, ROS A, B, C were determined as $0.30,0.15,0.45,0.60,1.0 \mathrm{ppm}$, respectively. The outcomes were shown in Table 4 . The correlation coefficient values assessed the calibration curve. The method was found linear over the concentration series from 0.30 to $7.5 \mathrm{ppm}, 0.15$ to 0.6 ppm, 0.45 to $1.8 \mathrm{ppm}, 0.6$ to $3 \mathrm{ppm}$ and 1.0 to $3.6 \mathrm{ppm}$ for

\section{TABLE 2: DETAILED METHOD DEVELOPMENT TRIALS}

\begin{tabular}{|c|c|c|c|c|c|c|}
\hline Trial \# & Column & $\begin{array}{c}\text { Flow, } \\
(\mathrm{ml} / \mathrm{min})\end{array}$ & $\begin{array}{c}\text { Gradient program, } \\
(\mathrm{T} / \% \mathrm{~B})\end{array}$ & $\begin{array}{c}\text { Void time, } \\
\text { min }\end{array}$ & $\begin{array}{c}\text { MET, } \\
\text { min }\end{array}$ & Remarks \\
\hline 1 & \multirow{2}{*}{$\begin{array}{l}\text { YMC-Pack ODS-A } \\
100 \times 4.6 \mathrm{~mm} ; 3 \mu \mathrm{m}\end{array}$} & 1.2 & $\begin{array}{c}0 / 35,30 / 50,35 / 55 \\
45 / 80,47 / 35 \text { and } 50 / 35\end{array}$ & 1 & 1 & MET eluted in void time \\
\hline 2 & & 1.2 & $\begin{array}{c}0 / 30,5 / 30,10 / 45 \\
30 / 45,35 / 55,45 / 80 \\
47 / 30 \text { and } 50 / 30\end{array}$ & 1 & 1 & MET eluted in void time \\
\hline 3 & $\begin{array}{c}\text { Unisol, C18; } \\
150 \times 4.6 \mathrm{~mm}, 3 \mu \mathrm{m}\end{array}$ & 0.9 & $\begin{array}{c}0 / 30,5 / 30,10 / 50 \\
30 / 50,40 / 80,42 / 30 \text { and } \\
45 / 30\end{array}$ & 1.3 & 1.5 & $\begin{array}{l}\text { MET retained more due to high carbon } \\
\text { loading of Unisol column. However, } \\
\text { ROS C not eluted within } 40 \text { minutes }\end{array}$ \\
\hline 4 & \multirow{2}{*}{$\begin{array}{l}\text { YMC-Pack ODS-A } \\
100 \times 4.6 \mathrm{~mm} ; 3 \mu \mathrm{m}\end{array}$} & 0.9 & $\begin{array}{c}0 / 30,5 / 30,10 / 45 \\
30 / 45,35 / 55,45 / 80 \\
47 / 30 \text { and } 50 / 30\end{array}$ & 1.3 & 1.5 & $\begin{array}{l}\text { MET got eluted after void time. } \\
\text { However, looking for the more } \\
\text { economical method regarding runtime }\end{array}$ \\
\hline 5 & & 0.9 & $\begin{array}{c}0 / 30,5 / 30,10 / 50 \\
30 / 50,40 / 80,42 / 30 \text { and } \\
45 / 30\end{array}$ & 1.3 & 1.5 & $\begin{array}{c}\text { The resolution between ROS and ROS B } \\
\text { got down, and MET got eluted in void } \\
\text { time, so trial } 4 \text { is the better one to } \\
\text { select }\end{array}$ \\
\hline
\end{tabular}

Buffer: $3.5 \mathrm{pH}$ of $20 \mathrm{mM}$ ammonium acetate adjusted $\mathrm{pH}$ with $\mathrm{H}_{3} \mathrm{PO}_{4}$. Mobile phase $\mathrm{A}:$ 9:1, v/v (buffer: acetonitrile), mobile phase $\mathrm{B}: 3: 5: 2$, $\mathrm{v} / \mathrm{v} / \mathrm{v}$ (buffer: acetonitrile:methanol) 
MET, ROS, ROS A, ROS B, and ROS C, respectively. The detailed parameters for the regression analysis are given in Table 4 . The recovery values obtained were between 98.7 and $101.9 \%$. The precision of recoveries was found to be $<2.5 \%$. The outcomes situated in Table 4. Significant changes were observed in ROS A and $\mathrm{C}$ impurities at room temperature $\left(25^{\circ}\right)$. The results were found to be stable for up to $3 \mathrm{~d}$ at refrigerator $\left(5^{\circ}\right)$,

TABLE 3: DEGRADATION STUDIES

\begin{tabular}{lccccccc}
\hline Stress condition & Peak & Assay, \% & Degradation, \% & PA & PT & PF & Mass balance \\
\hline As is sample & MET & 98.6 & 0.3 & 0.24 & 0.92 & NO & NA \\
& ROS & 99.4 & 0.3 & 0.03 & 0.26 & NO & NA \\
Neutral at $80^{\circ}$ for $4 \mathrm{~h}$ & MET & 97.3 & 0.0 & 0.22 & 1.00 & NO & 99 \\
& ROS & 96.5 & 1.2 & 0.07 & 0.26 & NO & 98 \\
$0.1 \mathrm{~N} \mathrm{HCl}$ at $80^{\circ}$ for $4 \mathrm{~h}$ & MET & 98 & 0.0 & 0.24 & 0.89 & NO & 99 \\
& ROS & 60.3 & 35.7 & 0.05 & 0.22 & NO & 97 \\
$0.1 \mathrm{~N} \mathrm{NaOH}$ at $80^{\circ}$ for $4 \mathrm{~h}$ & MET & 93.2 & 2.7 & 0.23 & 0.88 & NO & 97 \\
& ROS & 91.2 & 5.6 & 0.06 & 0.25 & NO & 97 \\
$3 \% \mathrm{H}_{2} \mathrm{O}_{2}$ at $80^{\circ}$ for $4 \mathrm{~h}$ & MET & 97.3 & 0.1 & 0.19 & 0.96 & NO & 99 \\
Thermal at $105^{\circ}$ for a week & ROS & 92.4 & 4.9 & 0.03 & 0.25 & NO & 98 \\
& MET & 97.5 & 0.1 & 0.19 & 0.99 & NO & 99 \\
Photolytic & ROS & 97.6 & 1.0 & 0.04 & 0.27 & NO & 99 \\
& MET & 98 & 0.0 & 0.22 & 0.96 & NO & 99 \\
Neutral at $80^{\circ}$ for $4 \mathrm{~h}$ & ROS & 91.7 & 6.7 & 0.04 & 0.26 & NO & 99 \\
& ROS A & NA & NA & 0.06 & 0.75 & NO & NA \\
& ROS B & NA & NA & 0.04 & 0.56 & NO & NA \\
\hline
\end{tabular}

PT: Purity threshold; PA: purity angle; PF: purity flag; NA: not applicable

a.

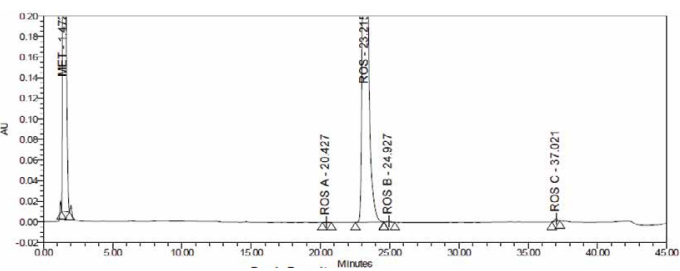

c.

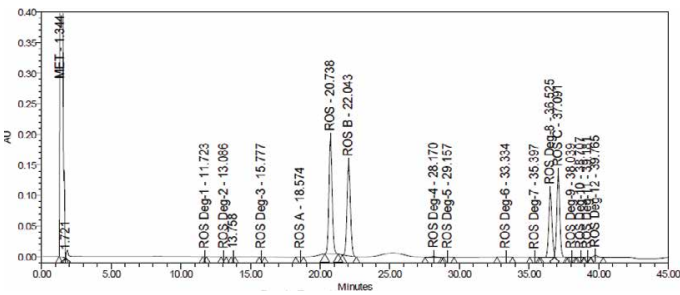

e.

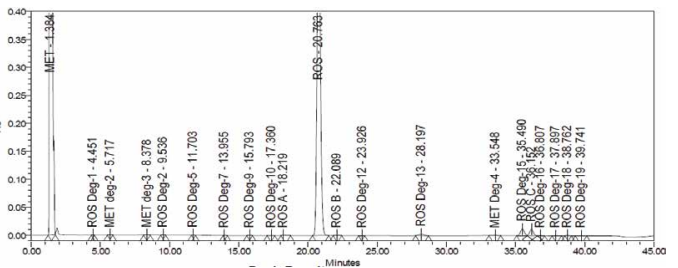

b.

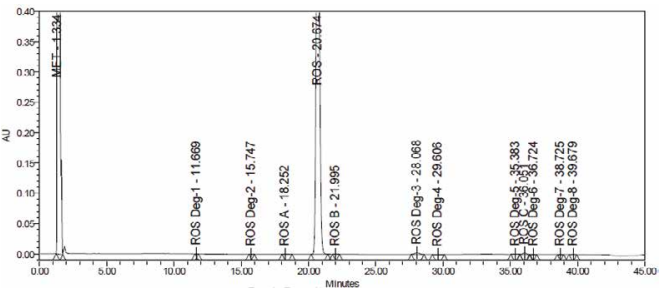

d.
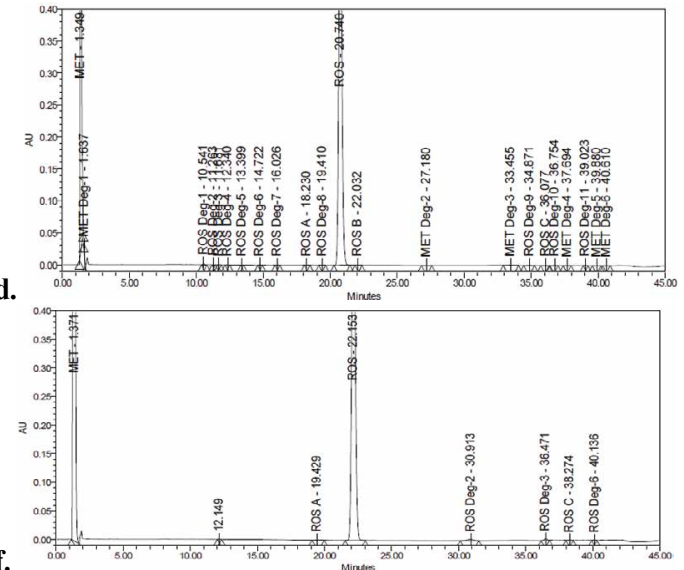

g.

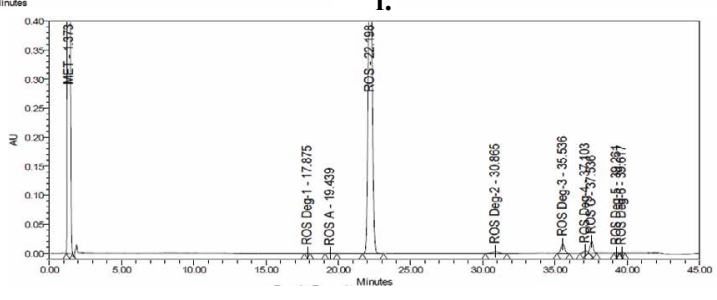

Fig. 2: Representative chromatograms

a. Trial 4; b. neutral degradation; c. acidic degradation; d. alkaline degradation; e. oxidative degradation; f. thermal degradation; g. photolytic degradation 
TABLE 4: VALIDATION PARAMETERS OF THE PROPOSED RP-HPLC METHOD

\begin{tabular}{lccccc}
\hline Parameter & MET & ROS & ROS A & ROS B & ROS C \\
\hline Range, ppm & $0.30-7.5$ & $0.15-0.6$ & $0.45-1.8$ & $0.6-3$ & $1.0-3.6$ \\
Regression equation & $y=37105 x-$ & $y=53998 x-$ & $y=26885 x-$ & $y=$ & $y=$ \\
Correlation coefficient & 994.03 & 196.12 & 386.06 & $20606 x+106.15$ & $7880.8 x+316.59$ \\
LOD, ppm & 0.9999 & 0.9998 & 0.9993 & 0.9998 & 0.9991 \\
LOQ, ppm & 0.1 & 0.05 & 0.15 & 0.2 & 0.4 \\
Accuracy \pm SD & 0.3 & 0.15 & 0.45 & 0.6 & 1 \\
Repeatability, \% RSD & - & - & $100.33 \pm 2.128$ & $100.18 \pm 1.778$ & $100.78 \pm 1.63$ \\
Intermediate precision, \% RSD & 0.2427 & 0.9315 & 2.4777 & 1.7874 & 1.9122 \\
\hline
\end{tabular}

TABLE 5: SOLUTION STABILITY RESULTS AT $25^{\circ}$ AND $5^{\circ}$

\begin{tabular}{lcccccc}
\hline \multirow{2}{*}{ Time } & \multicolumn{3}{c}{ Concentration at 25 $\%$} & \multicolumn{3}{c}{ Concentration at $5^{\circ}, \%$} \\
\cline { 2 - 7 } & ROS A & ROS B & ROS C & ROS A & ROS B & ROS C \\
\hline Initial & 0.3 & 0.499 & 0.594 & 0.301 & 0.498 & 0.594 \\
day & 0.299 & 0.498 & 0.583 & 0.299 & 0.498 & 0.591 \\
Variation, \% & 0.3 & 0.2 & 1.9 & 0.7 & 0 & 0.5 \\
2 days & 0.292 & 0.497 & 0.579 & 0.298 & 0.497 & 0.588 \\
Variation, \% & 2.7 & 0.4 & 2.5 & 1 & 0.2 & 1 \\
3 days & 0.2848 & 0.495 & 0.562 & 0.297 & 0.496 & 0.585 \\
Variation, \% & 5.1 & 0.8 & 5.4 & 1.3 & 0.4 & 1.5 \\
Specification, $<=\%$ & & 5 & & & 5 & \\
\hline
\end{tabular}

TABLE 6: THE IN-HOUSE AND MARKETED GENERIC TABLET ANALYSIS (\%)

\begin{tabular}{lcccccc}
\hline Sample details & ROS A & ROS B & ROS C & $\begin{array}{c}\text { Maximum } \\
\text { unknown of ROS }\end{array}$ & $\begin{array}{c}\text { Maximum } \\
\text { unknown of MET }\end{array}$ & $\begin{array}{c}\text { Total } \\
\text { impurities }\end{array}$ \\
\hline Generic MET SR-1/ROS IR-1 & 0.07 & ND & ND & 0.07 & 0.04 & 0.22 \\
Generic MET SR-1/ROS IR-2 & 0.03 & 0.13 & 0.21 & 0.06 & 0.04 & 0.7 \\
Generic MET SR-2/ROS IR-1 & 0.08 & ND & ND & 0.06 & 0.05 & 0.21 \\
Generic MET SR-2+ROS IR-2 & 0.05 & 0.09 & 0.16 & 0.04 & 0.02 & 0.03 \\
In-house tablets MET SR/ROS IR & 0.11 & ND & 0.15 & 0.1 & 0.1 & 0.39 \\
Specification, <= $\%$ & 0.3 & 0.5 & 0.6 & 0.1 & 2 \\
\hline
\end{tabular}

ND: Not detected

and the results are as shown in Table 5. Impurities for both in-house and individual generic marketed dosage forms of MET SR- ROS IR were found to be within the specification (Table 6). Therefore, this procedure can be applied successfully for regular examination of MET-ROS combination OSDF.

\section{Acknowledgement:}

Authors thank the Ashland India Pvt. Ltd. for support regarding instrumentation and chemicals.

\section{REFERENCES}

1. Chhetri HP, Thapa P, Van Schepdael A. Simple HPLCUV method for the quantification of metformin in human plasma with one-step protein precipitation. Saudi Pharm J 2014;22(5):483-7.

2. Shenfield G. Metformin: myths, misunderstandings, and lessons from history. Aust Prescr 2013;36:38-9.

3. Campbell IW, Howlett HC. Worldwide Experience of
Metformin as an Effective Glucose-lowering Agent: A Metaanalysis. Diabetes Metab Res Rev 1995;11Suppl 1:S57-S62.

4. He L, Sabet A, Djedjos S, Miller R, Sun X, Hussain MA, et al. Metformin and insulin suppress hepatic gluconeogenesis through phosphorylation of CREB binding protein. Cell 2009;137(4):635-46.

5. Hundal RS, Krssak M, Dufour S, Laurent D, Lebon $\mathrm{V}$, Chandramouli $\mathrm{V}$, et al. Mechanism by which metformin reduces glucose production in type 2 diabetes. Diabetes 2000;49(12):2063-9.

6. Stumvoll M, Nurjhan N, Perriello G, Dailey G, Gerich JE. Metabolic effects of metformin in non-insulin-dependent diabetes mellitus. N Engl J Med 1995;333(9):550-4.

7. Vander Heiden MG, Cantley LC, Thompson CB. Understanding the Warburg effect: the metabolic requirements of cell proliferation. Science 2009;324(5930):1029-33.

8. Cetin M, Sahin S. Microparticulate and nanoparticulate drug delivery systems for metformin hydrochloride. Drug Deliv 2016;23(8):2796-805.

9. Dowling RJ, Goodwin PJ, Stambolic V. Understanding the benefit of metformin use in cancer treatment. BMC Med 2011;9:33.

10. Zakikhani M, Dowling R, Fantus IG, Sonenberg N, Pollak M. 
Metformin is an AMP kinase-dependent growth inhibitor for breast cancer cells. Cancer Res 2006;66(21):10269-73.

11. Beludari MI, Prakash KV, Mohan GK. RP-HPLC method for simultaneous estimation of Rosuvastatin and Ezetimibe from their combination tablet dosage form. Int J Chem Anal Sci 2013:4;205-9.

12. Janardhanan VS, Manavalan R, Valliappan K. Chemometric technique for the optimization of chromatographic system: Simultaneous HPLC determination of rosuvastatin, telmisartan, ezetimibe and atorvastatin used in combined cardiovascular therapy. Arabian J Chem 2012;9:S1378-87.

13. Brown AF, Mangione CM, Saliba D, Sarkisian CA. California Healthcare Foundation/American Geriatrics Society Panel on Improving Care for Elders with Diabetes.. Guidelines for improving the care of the older person with diabetes mellitus. J Am Geriatr Soc 2003;51(5 Suppl Guidelines):65-80.

14. Brunzell JD, Davidson M, Furberg CD, Goldberg RB, Howard $\mathrm{BV}$, Stein $\mathrm{JH}$, et al. Lipoprotein management in patients with cardiometabolic risk: consensus conference report from the American Diabetes Association and the American College of Cardiology Foundation. J Am Coll Cardiol 2008;51(15):151224.

15. Olsson AG, Pears J, McKellar J, Mizan J, Raza A. Effect of rosuvastatin on low-density lipoprotein cholesterol in patients with hypercholesterolemia. Am J Cardiol 2001;88(5):504-8.

16. Paoletti R, Fahmy M, Mahla G, Mizan J, Southworth H. Rosuvastatin demonstrates greater reduction of low-density lipoprotein cholesterol compared with pravastatin and simvastatin in hypercholesterolaemic patients: a randomized, double-blind study. J Cardiovasc risk 2001;8(6):383-90.

17. Davidson M, Ma P, Stein EA, Gotto AM, Raza A, Chitra $\mathrm{R}$, et al. Comparison of effects on low-density lipoprotein cholesterol and high-density lipoprotein cholesterol with rosuvastatin versus atorvastatin in patients with type IIa or IIb hypercholesterolemia. Am J Cardiol 2002;893:268-75.

18. H. Suh, M. Chun, T. An, J. Choi, H. Seo, J. Lim, et al. Pharmaceutical composition comprising metformin and rosuvastatin. United States patent US2013/0035316 A1. 2013.

19. Kumar PP, Murthy TE, Rao MB. Development, validation of liquid chromatography-tandem mass spectrometry method for simultaneous determination of rosuvastatin and metformin in human plasma and its application to a pharmacokinetic study. J Adv Pharm Technol 2015;6(3):118-24.

20. Murthy TG, Geethanjali J. Development of a Validated RPHPLC Method for Simultaneous Estimation of Metformin Hydrochloride and Rosuvastatin Calcium in Bulk and InHouse Formulation. J Chromatogr Sep Tech 2014;5:1.
21. Vlassara H. Recent progress in advanced glycation end products and diabetic complications. Diabetes 1997;46(Suppl 2):S19-25.

22. Bierman EL. George Lyman Duff Memorial Lecture. Atherogenesis in diabetes. Arterioscler Thromb Vasc Biol 1992;12:647-56.

23. Lamharzi N, Renard CB, Kramer F, Pennathur S, Heinecke JW, Chait A, et al. Hyperlipidemia in concert with hyperglycemia stimulates the proliferation of macrophages in atherosclerotic lesions. Diabetes 2004;53:3217-25.

24. Arayne MS, Sultana N, Tabassum A. RP-LC simultaneous quantitation of co-administered drugs for (non-insulin dependent) diabetic mellitus induced dyslipidemia in active pharmaceutical ingredient, pharmaceutical formulations and human serum with UV-detector. Clin Chim Acta 2013;425:5461.

25. Antonopoulos N, Machairas G, Migias G, Vonaparti A, Brakoulia V, Pistos C, et al. Hydrophilic Interaction Liquid Chromatography-Electrospray Ionization Mass Spectrometry for Therapeutic Drug Monitoring of Metformin and Rosuvastatin in Human Plasma. Molecules 2018;23(7):1548.

26. ICH Harmonized Tripartite. Validation of analytical procedures: text and methodology Q2 (R1). Geneva, Switzerland: International Conference on Harmonization. 2005. p. 11-12. Available from: https://www.ich.org/fileadmin/ Public_Web_Site/ICH_Products/Guidelines/Quality/Q2_R1/ Step4/Q2_R 1 _ Guideline.pdf.

27. Snyder LR, Kirkland JJ, Glajch JL. Practical HPLC method development. Hoboken, NJ, USA: John Wiley \& Sons; 2012.

28. Bakshi M, Singh S. Development of validated stabilityindicating assay methods-critical review. J Pharm Biomed Anal 2002;28:1011-40.

29. Blessy MR, Patel RD, Prajapati PN, Agrawal YK. Development of forced degradation and stability indicating studies of drugs - A review. J Pharm Anal 2014;4:159-65.

30. Guideline, ICH Harmonized Tripartite. Stability testing of new drug substances and products. Q1A (R2), 2003. p. 1-24. Available from: https:/www.ich.org/fileadmin/Public_Web_ Site/ICH_Products/Guidelines/Quality/Q1A_R2/Step4/Q1A_ R2_Guideline.pdf.

31. Drug DP. Guidance for industry. Center for Drug Evaluation and Research (CDER). 1998. 1000. Available from: https:// www.fda.gov/downloads/Drugs/Guidances/ucm070561.pdf.

32. Food and Drug Administration. Center for drug evaluation and research Reviewer guidance, validation of chromatographic methods. 1994. Available from: https://www.fda.gov/ downloads/drugs/guidances/ucm134409.pdf. 